\title{
NEUROVASCULAR CONTROL OF OXYGEN TENSION IN THE TESTIS AND EPIDIDYMIS
}

\author{
B. A. CROSS AND I. A. SILVER \\ Sub-Department of Veterinary Anatomy, \\ University of Cambridge
}

(Received 9th August 1961)

\begin{abstract}
Summary. Interstitial oxygen tension was recorded polarographically with gold-plated needle electrodes in the testis and cauda epididymidis of the rabbit, sheep and dog. The mean epididymal resting oxygen tension was about twice that of the testis in the rabbit and sheep, and nearly three times testis oxygen tension in the dog. A short period of oxygen breathing doubled testicular oxygen tension while nitrous oxide breathing more than halved it. The latency of the testis response was always much longer than that of the epididymal response in the rabbit and sheep, but only slightly longer in the dog. The discrepancy was accounted for by the arterial arrangement in the three species. Occlusion of the internal spermatic artery produced a drastic fall in testis oxygen tension in the rabbit, sheep and dog, and had little effect on epididymal oxygen tension. Vasal artery occlusion reduced oxygen tension in the cauda epididymidis but not the testis, and a large fall occurred only if collateral vessels from the internal spermatic or cremasteric arteries were also clamped. Circulatory hypotension produced by amyl nitrite inhalation reduced oxygen tension in the testis and epididymis of all three species.

Local cooling of the scrotum depressed oxygen tension in the ipsilateral testis of the rabbit, sheep and dog. Conversely, local warming of the scrotum produced a rise of oxygen tension in the ipsilateral testis. Thoraco-lumbar spinal anaesthesia did not block these effects. Electrical stimulation of the sympathetic areas of the hypothalamus in the rabbit elicited a profound depression of testicular oxygen tension characterized by an initial rapid phase, which was abolished by posterior mesenteric ganglionectomy and hypogastric nerve section, and a secondary slower phase, which was abolished by adrenalectomy. The two phases could be mimicked by stimulation of the posterior mesenteric ganglion or hypogastric nerves, and by intravenous injection of adrenaline respectively.
\end{abstract}

\section{INTRODUGTION}

Most text-book accounts of the physiology of the male genital tract devote much space to the actions of the androgens and to hormonal influences on 
spermatogenesis. They have little to say on contractile or vascular mechanisms in the testis or epididymis, though both may be of some consequence to sperm production and fertility. A number of recent studies have drawn attention to the special importance of testicular blood supply. The experiments of Harrison (1949) and others leave no doubt that interference with the circulation to the testicle can gravely impair sperm production, and some authors (Moore, 1924; Harrison, 1956) suggest that the damaging effects of cryptorchidism and scrotal warming on fertility may be of vascular origin. Dahl \& Herrick (1959) have investigated the thermal exchange properties of the counter-current mechanism formed by the internal spermatic artery and the veins of the pampiniform plexus in the dog; while Waites \& Moule (1960) have reported on certain haemodynamic aspects of the same structure in the sheep. We now have reason to suppose that the circulatory architecture of the testicle presents unique features which are not without physiological significance. There is an urgent need for further studies directed towards the nervous and humoral mechanisms regulating the circulation of blood through the testis and epididymis.

Inasmuch as tissue oxygen tension is largely determined by capillary blood flow, the polarographic recording of oxygen tension with needle electrodes thrust into the substance of the testis and epididymis could be expected to provide a convenient method of monitoring circulatory changes in these organs. This expectation, which was aroused by our polarographic observations on the brain (Cross \& Silver, 1962a) and mammary gland (Cross \& Silver, 1962b), has been confirmed by experiments described in the present paper. We have, therefore, made use of the method to study local and systemic mechanisms, both nervous and humoral in nature, that appear to exercise a regulatory influence on testicular circulation.

\section{MATERIALS AND METHODS}

\section{ANIMALS}

The animals used for these experiments comprised thirteen adult male crossbred rabbits weighing between 2.4 and $3.5 \mathrm{~kg}$, three yearling Soay rams and two dogs, a 9-month-old crossbred alsatian and a 2-year-old greyhound. All, except for the three sheep, were used in acute experiments. The sheep were kept in a pen at the laboratory and fed on a diet of oats, hay, straw and water ad lib. for 6 weeks during which period observations were made on the testicular oxygen tension of each sheep at fortnightly intervals.

\section{ANAESTHESIA}

Rabbits were anaesthetized with urethane given as a $20 \%$ aqueous solution in a dose of $1 \mathrm{~g} / \mathrm{kg}$, two-thirds of which was injected intravenously and the remainder intraperitoneally. Further intravenous doses were given if necessary during the course of the experiments. When required, thoraco-lumbar spinal anaesthesia was induced by injection of $\mathrm{I}$ to $1.5 \mathrm{ml} 2 \%$ Lignocaine hydrochloride (Xylocaine, Duncan \& Flockhart Ltd) through the lumbo-sacral 
space as previously described (Cross, 1958). This produced immediate loss of hind-limb reflexes and loss of tone in abdominal musculature, but spontaneous respiration was maintained.

The dogs were anaesthetized with intravenous sodium pentobarbitone (Nembutal, Abbott Laboratories Ltd) at the dose rate of $25 \mathrm{mg} / \mathrm{kg}$ after premedication with chlorpromazine (Largactil, May \& Baker \& Co) in a dose of $0.5 \mathrm{mg} / \mathrm{kg}$ intravenously. Further injections of nembutal were given as required through an indwelling needle in the jugular vein. A cuffed McGill tube was inserted into the trachea and inflated.

The sheep were anaesthetized and intubated in the same manner as the dogs for terminal observations. Measurements of testicular oxygen tension were made on conscious sheep sedated with intravenous chlorpromazine $(0.5 \mathrm{mg} / \mathrm{kg})$ and gently restrained on a couch. A small area of scrotal skin was anaesthetized with $2 \%$ Xylocaine at the site selected for electrode insertions.

\section{OPERATION PROCEDURES}

The heads of the anaesthetized rabbits were secured in a stereotaxic instrument and a short piece of rubber tubing was inserted through the mouth into the pharynx and held in place by a tape round the muzzle. A glass T-piece was inserted into the tube, one arm of which was connected to a Boyle's anaesthetic apparatus for administering oxygen or nitrous oxide, while the other was open to room air.

When it was necessary to perform experimental manipulations of structures within the abdominal cavity, a mid-line laparotomy incision was made and the mobile viscera were placed in a polythene bag containing warm normal saline solution. This procedure greatly facilitated exposure of the male organs and their nerve and blood supply. All exposed parts were kept moist with warm saline solution, and whenever possible covered with polythene sheeting to minimize drying and cooling. The animals were kept warm on the operating table by means of an electrically heated blanket. Diathermy electrodes were used for destroying posterior mesenteric ganglia and/or hypogastric nerves and for coagulating adrenal glands before their removal when adrenalectomy was required. Similar procedures were carried out in the dog and sheep, but in the latter species ruminal contents were first aspirated before placing the viscera in a polythene bag.

\section{OXYGEN-TENSION RECORDING}

Oxygen tension was measured polarographically by the method described in detail by Cater, Silver \& Wilson (1959; see also Cater, 1960, and Cater \& Silver, 1961). In the present application, the recording electrodes were made from straight intestinal needles of austenitic stainless steel, the ends of which were reduced to fine points by electropolishing in $50 \%$ hydrochloric acid. These needles were then insulated with five to six coats of epoxy resin (Araldite 985E, CIBA A.R.L., Duxford, England). The tips were freed of Araldite by 
grinding on a soft hone, and then electroplated, first with copper and finally with gold. The electrodes were calibrated immediately before use and the calibration checked at the end of the experiment to avoid errors due to damage to the tips in the course of insertion into the tissues. The indifferent electrode was a silver/silver chloride wire inserted subcutaneously. A polarizing voltage of 0.6 volts was applied via the indifferent electrode and the resultant minute current at the gold cathode (proportional to the concentration of dissolved oxygen) was amplified and fed to a galvanometer. The galvanometer readings were recorded manually and later converted to oxygen-tension values.

\section{STIMULATION PROCEDURES}

Oxygen or nitrous oxide was supplied to the animals from a Boyle's anaesthetic apparatus. An open circuit system was used for rabbits, oxygen was supplied at 1.5 to $21 . / \mathrm{min}$ and nitrous oxide at $51 . / \mathrm{min}$ for periods of up to $30 \mathrm{sec}$. The gases were given on closed circuit to the sheep and dog and the expired carbon dioxide and water vapour were removed by soda-lime in a Water's absorber. In the unanaesthetized sheep, the gases were given on an open circuit via a Hall's dog mask applied to the muzzle.

Amyl nitrite was administered to rabbits by crushing a capsule and holding it to the side arm of the T-piece in the mouth tube. In the case of anaesthetized sheep and dogs, a crushed capsule was placed at the inlet of the endotracheal tube.

For electrical stimulation of the hypothalamus in the rabbit, a burr hole $4 \mathrm{~mm}$ wide was first made in the skull at the bregma suture and the dura was incised and reflected. The monopolar stimulating electrode consisted of $1 \mathrm{~mm}$ of fine platinum wire protruding from the end of a fine dental-type hypodermic needle insulated with several coats of Araldite. The electrode was fixed in a cylindrical perspex rod and lowered into the brain with the help of a micromanipulator. Accurate placement of the electrode tip in the lateral or posterior hypothalamic areas was assisted by use of the appropriate coordinates in the rabbit stereotaxic atlas of Sawyer, Green \& Everett (1954). The circuit was completed by an indifferent electrode in the form of a brass rod in the rectum. The stimulus parameters used were 10 to $20 \mathrm{sec}$., 0.75 to 1.0 volts (R.M.S. value) and $50 \mathrm{cyc} / \mathrm{sec}$ sine wave A.C. To excite the abdominal sympathetic nerves in rabbits, dogs and sheep the same stimulating circuit was used except that the brain electrode was replaced by a manually held platinum electrode with a glass handle. Stimuli of 1 to 3 volts applied for a few seconds were found to be effective.

Various methods were tried for occluding blood vessels to the testis and epididymis including bowel forceps, bull-dog clips and Spencer-Wells forceps, but digital pressure was found to be most efficient and least traumatic procedure, and was, therefore, adopted as routine in this work.

Adrenaline injections were given in normal saline solution into the marginal ear vein of rabbits and via an indwelling needle in the jugular vein of sheep and dogs. The agent employed was 'Adrenaline Tartrate' (Burroughs, Wellcome \& Co) containing $1: 1000$ adrenaline. 


\section{RESULTS}

RELATION BETWEEN TESTICULAR OXYGEN TENSION AND BLOOD SUPPLY

\section{Resting oxygen tension in testis and epididymis}

The gold-plated tips of the electrodes used in these experiments were conical in shape (base $0.25 \mathrm{~mm}$, length 0.5 to $1 \mathrm{~mm}$ ), so that when thrust into the substance of the testis or epididymis the oxygen tension recorded represented a mean value for a volume of tissue that could be expected to contain a number of capillaries as well as parenchymatous and interstitial elements. The size of the electrode tips precluded any possibility of recording from inside tubules. Immediately after insertion of the electrode, the galvanometer needle usually registered a slow fall of oxygen tension, but during the course of the next few minutes the readings rose to a steady value which was then maintained. We believe the initial fluctuations were due to a temporary mechanical interference with local capillary blood flow caused by passage of the electrode tip through the tissue. The resting levels of oxygen tension recorded in the testes of thirteen rabbits under urethane anaesthesia varied from 7 to $14 \mathrm{~mm} \mathrm{Hg}$ with a mean value of $11.6 \pm 0.6$ (S.E.). In eight of these animals, measurements were also made in the cauda epididymidis where oxygen tensions ranging from 15 to $26 \mathrm{~mm} \mathrm{Hg}$ were obtained, with a mean value of $21 \cdot 8 \pm 1.5$ (s.E.). There was thus no overlap in the oxygen tensions recorded in the two organs and usually the testis had a tension about half that of the cauda epididymidis.

Very similar figures for oxygen tension in testis and cauda epididymidis were found in the three sheep, in which the mean value in $\mathrm{mm} \mathrm{Hg}$ for testis was $11.4 \pm 0.5$ (S.E.) and that for epididymis was $21.7 \pm 2.9$ (s.E.). Oxygen tension measurements were made in these animals on several occasions both with and without a general anaesthetic, and there appeared to be no obvious difference in resting tension in the conscious and unconscious state. The oxygen tension in testis ranged from 8 to $15 \mathrm{~mm} \mathrm{Hg}$ in conscious animals and 7 to $14 \mathrm{~mm} \mathrm{Hg}$ under nembutal anaesthesia, while the corresponding ranges for epididymis were 16 to $34 \mathrm{~mm} \mathrm{Hg}$ in the conscious, and 13 to $23 \mathrm{~mm} \mathrm{Hg}$ in the nembutalized sheep.

An even greater disparity in the resting oxygen tension recorded from the testis and cauda epididymidis was observed in the two dogs under nembutal anaesthesia. The first animal had an oxygen tension of $9 \mathrm{~mm} \mathrm{Hg}$ in testis and $24 \mathrm{~mm} \mathrm{Hg}$ in epididymis, and the corresponding figures for the second dog were $7 \mathrm{~mm} \mathrm{Hg}$ and $19 \mathrm{~mm} \mathrm{Hg}$.

\section{Effect of oxygen and nitrous oxide breathing}

Soon after starting every experiment, the animals were given pure oxygen to breathe for a short period in order to check the recording system and the effective placement of the electrodes. Usually, a sharp rise in oxygen tension was recorded amounting to $200 \%$ or more of the initial level (Text-fig. 1). The level of oxygen tension rapidly descended to the original resting value on resumption of air breathing. Nitrous oxide breathing brought about the reverse sequence of changes with a fall of oxygen tension of 50 to $90 \%$ followed by recovery to normal levels when room air was again breathed. Occasionally, 
very little change occurred following oxygen or nitrous oxide breathing, and this lack of responsiveness we attributed to the location of the electrode tip: either in trabecular connective tissue or in a zone of haemorrhage caused by puncturing a small blood vessel. In such cases, moving the electrode to a fresh site in the organ sufficed to restore sensitivity to oxygen-tension changes. These effects of oxygen and nitrous oxide inhalation were obtained in both the testis and the cauda epididymidis of the rabbit, dog and sheep (Text-figs. 1 and 2). It was noteworthy that in all three species the change of oxygen tension

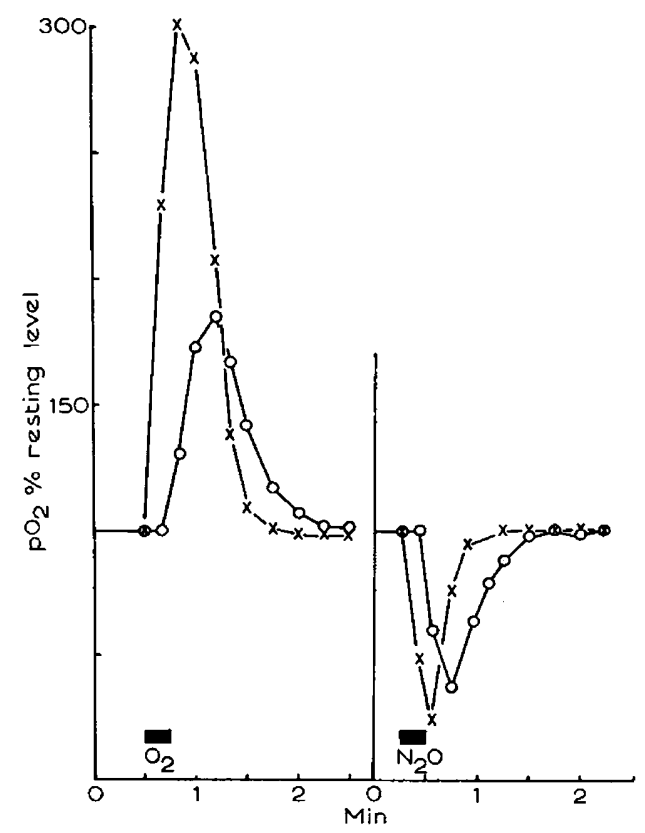

TExT-FIG. 1. Effect of oxygen and nitrous oxide breathing on the oxygen tension $\left(\mathrm{pO}_{2}\right)$ in the testis and cauda epididymidis of the rabbit.

$\times \longrightarrow \times$ Epididymis; $O \longrightarrow O$ Testis.

in the epididymis always preceded that in the testis. In the rabbit, for example, the needle of the galvanometer monitoring epididymal oxygen tension would start to rise about 5 sec after the onset of oxygen breathing, whereas the galvanometer needle registering testis oxygen tension remained stationary for a further 7 to $10 \mathrm{sec}$ before it, too, commenced to rise. A similar lag was seen in the return of the two galvanometer needles after the end of oxygen breathing, so that invariably at some point the needles were moving in opposite directions, i.e. oxygen tension was still rising in the testis when it was already falling in epididymis. In seven rabbits, repeated tests were made with a stop watch to determine these latencies. Very consistent figures were obtained in individual rabbits regardless of whether oxygen or nitrous oxide were used as the inspired gas. The mean latency for testis was $14 \mathrm{sec}$ (range 13 to $17 \frac{1}{2} \mathrm{sec}$ ). Thus an average interval of $8 \frac{1}{2} \mathrm{sec}$ elapsed between the responses in the epididymis and testis. In similar tests on the three sheep, we obtained mean 
latencies of $15 \mathrm{sec}$ for epididymis (range 13 to $17 \mathrm{sec}$ ) and $54 \mathrm{sec}$ for testis (range 46 to $60 \mathrm{sec}$ ), giving an average interval of $39 \mathrm{sec}$. In the dog, the latency of the epididymal response to oxygen or nitrous oxide breathing was similar to that in the sheep, i.e. 10 to $15 \mathrm{sec}$, but the latency of the response in



TEXT-FIG. 2. Effect of oxygen and nitrous oxide breathing on the oxygen tension ( $\mathrm{pO}_{2}$ ) in the testis and cauda epididymidis of the sheep.

$\times-\times$ Epididymis; $0-0$ Testis.

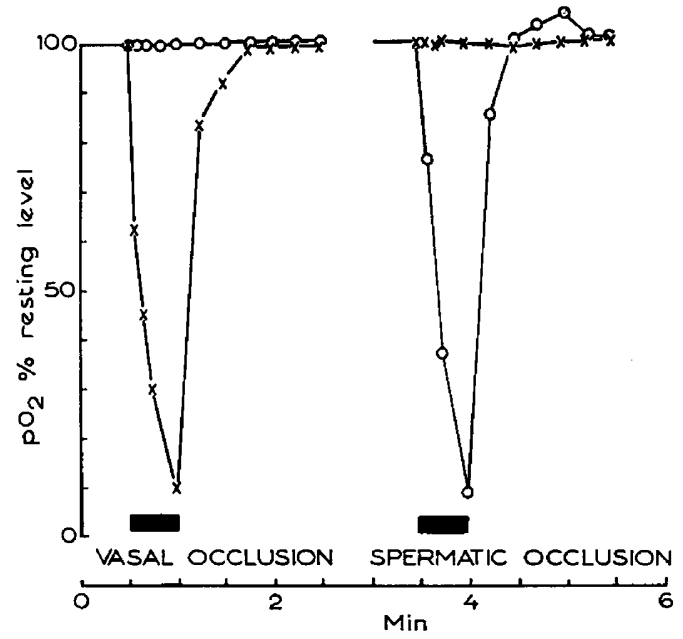

Text-FIG. 3. Effect of separately occluding the vasal and internal spermatic blood vessels on the oxygen tension $\left(\mathrm{pO}_{2}\right)$ in the testis and cauda epididymidis of the rabbit. $\times \longrightarrow \times$ Epididymis; $O \longrightarrow O$ Testis.

the testis was much shorter, i.e. 15 to $20 \mathrm{sec}$. These latency differences were evidently due to species variation in the circulation time of the blood from the lungs to the testis and epididymis, respectively. It was therefore necessary in making the above observations in the sheep and dog, which have low respiration rates, to take as zero time the first inspiration after turning on the test gas. 
A difficulty had been experienced in performing the latency tests in conscious sheep as placing the mask over the muzzle tended to inhibit respiration. Nevertheless, the difference in the latency between testis and epididymis was the same in the conscious and anaesthetized state.

Effects of occluding spermatic, vasal and cremasteric vessels

The experiment depicted in Text-fig. 3 clearly demonstrates the separate sources of the main blood supplies to the testis and cauda epididymidis in the rabbit. Occlusion of the vasal vessels for $30 \mathrm{sec}$ reduced the oxygen tension in the cauda by $90 \%$ while the testis oxygen tension remained undisturbed.

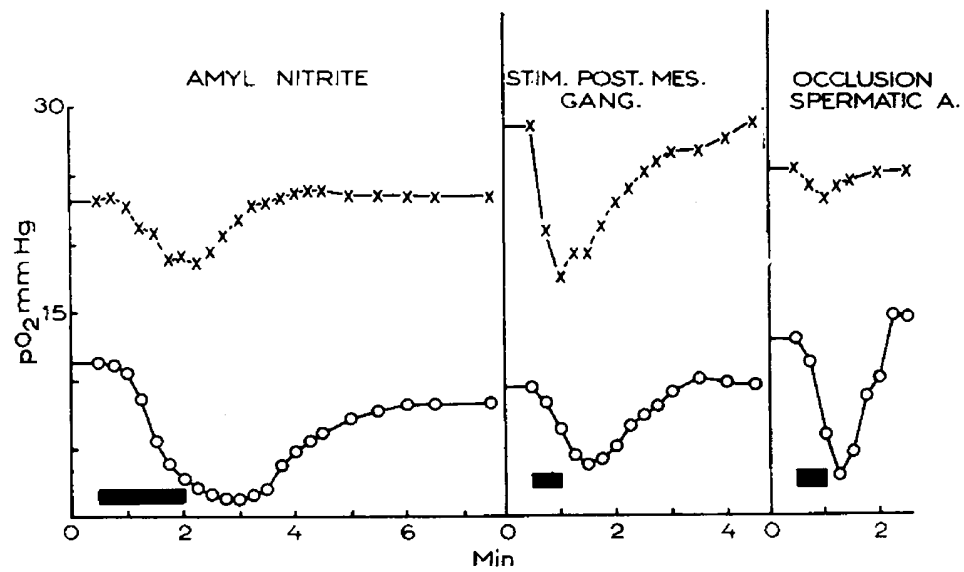

TexT-Fig. 4. Effect of inhaling amyl nitrite vapour, electrically stimulating the posterior mesenteric ganglion and occluding the internal spermatic artery on the oxygen tension $\left(\mathrm{pO}_{2}\right)$ in the testis and cauda epididymidis of the sheep.

$\times \longrightarrow \times$ Epididymis; $O \longrightarrow O$ Testis.

When the internal spermatic vessels were clamped, the testis oxygen tension was reduced $90 \%$ with no change in epididymal oxygen tension. This experiment was done after a laparotomy, with the testicle pushed through the inguinal canal into the abdomen and the gubernaculum ruptured. In another animal with the gubernaculum intact, we found that occlusion of the vasal vessels only caused a $42 \%$ drop of oxygen tension in the cauda epididymidis, which suggested to us that some collateral circulation might reach the organ from the cremasteric blood vessels. This suspicion was confirmed when clamping the cremasteric vessels resulted in a $20 \%$ fall in epididymal oxygen tension. Post-mortem injection of the cremasteric vessels with india ink confirmed the presence of anastomotic connexions in the gubernaculum between the vasal and cremasteric vascular beds (see also Pl. 1, Fig. 1). In both the sheep and dog, occlusion of the spermatic vessels greatly reduced the testis oxygen tension (65 to $92 \%$ ) while much less markedly affecting the oxygen tension of the cauda epididymidis (10 to $35 \%$ reduction, Text-fig. 4 ). In these species, vasal occlusion alone did not greatly depress oxygen tension in either testis or epididymis $(<29 \%)$, suggesting that a fairly efficient collateral supply from the spermatic or cremasteric vessels was available. 

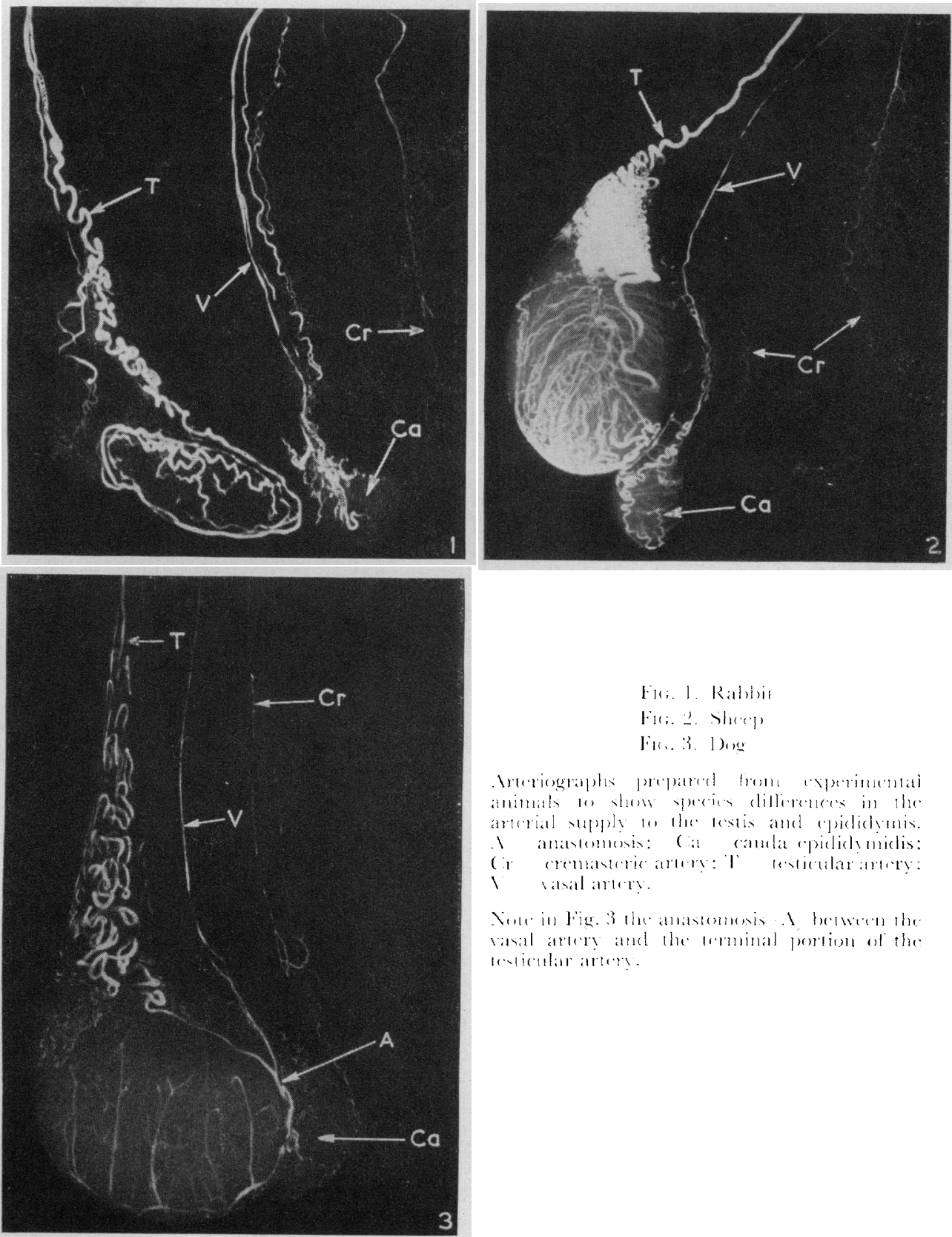

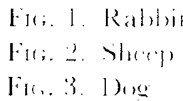

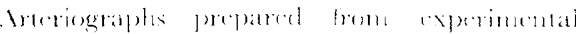

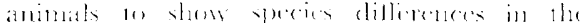

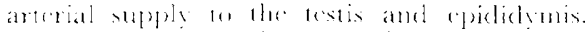

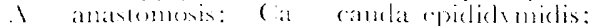

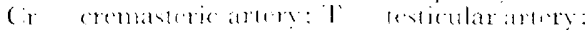
1 vatal artary.

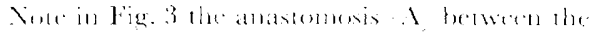
vasal atery and the tominal portion of the ralicular artr? 
A detailed study of the vascular supply of male organs in domestic mammals is being undertaken by our colleague, Mr D. H. Steven. Here we wish to draw attention only to one finding, which relates to the short latency of the change of testis oxygen tension in the dog following oxygen or nitrous oxide breathing (see above). When appropriate arteriographs (Plate 1) were prepared in the rabbit, sheep and dog, it was confirmed that all three species had a highly convoluted testicular artery within the pampiniform plexus. In the rabbit and sheep, this must be held chiefly responsible for the longer circulation time to the testis as compared with that to the cauda epididymidis, which involves the relatively straight vasal vessels. In the dog, however, the arteriographs (Pl. 1, Fig. 3) showed the presence of anastomotic connexions from the vasal artery, which pierced the tunica albuginea testis and linked with the terminal portions of the testicular artery within the testis itself. The anastomoses were

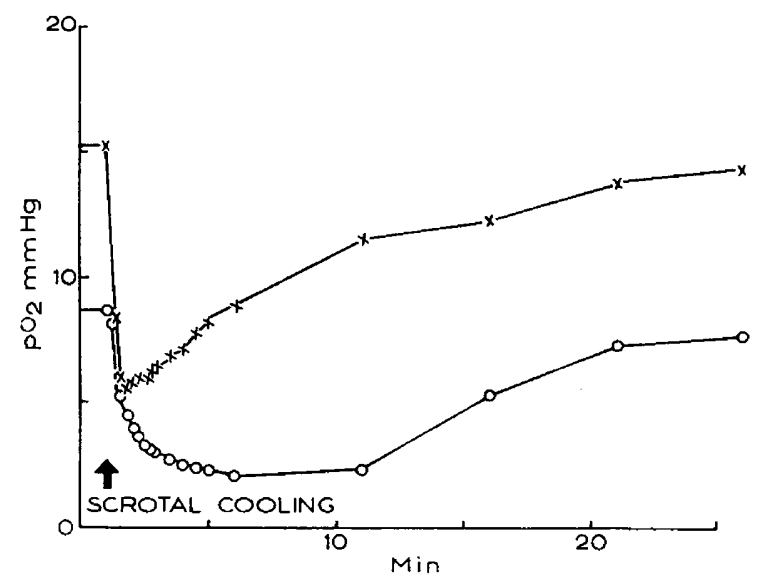

TEXT-FIG. 5. Effect of cooling the scrotum by spraying with ethyl chloride for $3 \mathrm{sec}$ on the oxygen tension $\left(\mathrm{pO}_{2}\right)$ in the ipsilateral testis and cauda epididymidis of the rabbit. $\times \stackrel{\longrightarrow \text { Epididymis; } 0 \longrightarrow}{\longrightarrow}$ Testis.

confirmed by dissection of the injected specimens. This arrangement of arterial vessels was described by Joranson, Emmel \& Pilka (1929). It seems likely, therefore, that admixture of blood from the vasal artery with that in the testicular artery had the effect of partially short-circuiting the coiled arterial passages through the pampiniform plexus and thus reducing the latency of the oxygen-tension response in the testis to oxygen or nitrous oxide inhalation.

\section{Effects of arterial hypotension induced by amyl nitrite inhalation}

The results of vascular occlusion experiments described above demonstrated the dependence of epididymal and testis oxygen tension on the blood flow through these organs. Further evidence on this point was sought by making use of the well established hypotensive effect of inhaling amyl nitrite vapour, which could be expected temporarily to produce an overall reduction in blood flow in the testis and epididymis.

It was difficult to standardize the amyl nitrite stimulus and the response 
was quite variable in degree. However, the direction of the change in oxygen tension was constant, namely a reduction of oxygen tension in both the testis and cauda epididymidis in the rabbit, sheep and dog. Usually, the response in the epididymis was less than that in the testis (Text-fig. 4). The mean reduction in oxygen tension in the epididymis was $22 \%$ (range 7 to $40 \%$ ) and that of the testis was $39 \%$ (range 8 to $89 \%$ ). The commencement of the fall in oxygen tension in the two organs occurred at about the same time but maximal depression of oxygen tension in the testis occurred after recovery had begun in the epididymis (Text-fig. 4).

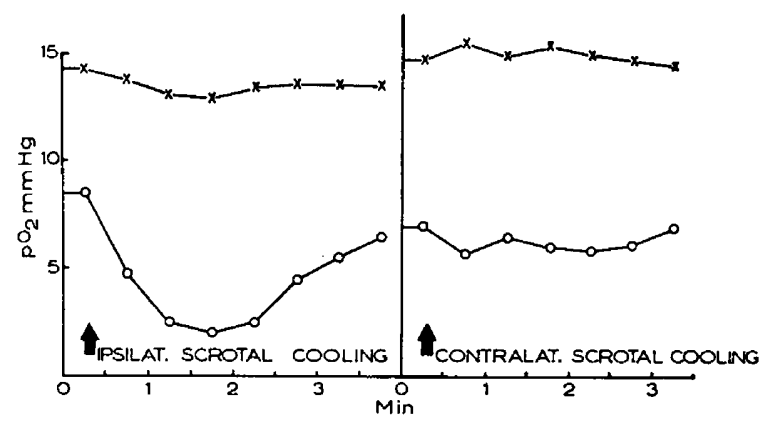

TEXT-FIG. 6. Effect of cooling the ipsilateral and contralateral halves of the scrotum with ethyl chloride spray on the oxygen tension $\left(\mathrm{pO}_{2}\right)$ in the testis and cauda epididymidis of the sheep.

$\times \longrightarrow \times$ Epididymis; $\mathrm{O} \longrightarrow \mathrm{O}$ Testis.

\section{SCROTAL INFLUENCES ON TESTICULAR BLOOD FLOW}

\section{Effect of scrotal cooling}

The scrotum was cooled in seven rabbits by spraying with ethyl chloride for $3 \mathrm{sec}$. This stimulus always resulted in a profound and prolonged depression of oxygen tension in the ipsilateral testis. The maximum reduction of tension occurred several minutes after the stimulus, i.e. at a time when the scrotal skin was no longer cold. The maximum depression of testis oxygen tension ranged from 72 to $90 \%$ and the responses lasted 15 to $30 \mathrm{~min}$. The oxygen tension of the cauda epididymidis also fell by 46 to $86 \%$, but recovery of oxygen tension in this organ always preceded that in the testis. The typical effects of scrotal cooling in the testis and epididymis of the rabbit are shown in Textfig. 5 .

Cooling the contralateral scrotum depressed testis oxygen tension only slightly $(<25 \%)$ and the cauda epididymidis registered a small $(<18 \%)$ change, up or down. Cooling the ear or paw had negligible effect on oxygen tension in either testis or epididymis. If the testicle were pushed into the abdomen and the gubernaculum ruptured, cooling the scrotum produced only a slight and transient fall in testis oxygen tension, and direct cooling of the testicle in the abdomen also had little effect. The necessary condition for maximal depression of testicular oxygen tension, which was presumably due to a vascular spasm, appeared to be the cooling of the ipsilateral scrotum with the testicle in situ. In three rabbits, thoraco-lumbar spinal anaesthesia was 
induced to determine if a spinal reflex mechanism were involved in this phenomenon. No impairment of the response to scrotal cooling resulted (Textfig. 7).

Similar experiments were carried out on sheep and dogs. Again, the invariable effect of scrotal cooling was to produce a diminution of oxygen tension in the testis ranging from 30 to $75 \%$. However, the extent and duration of the depression were smaller than those recorded in the rabbit. This was probably due to the standard cooling stimulus being relatively less powerful in the larger animals. The effect on the oxygen tension in the cauda epididymidis was small and variable in direction (Text-fig. 6). In the sheep experiments we observed no obvious difference in the responses of conscious and anaesthetized animals.

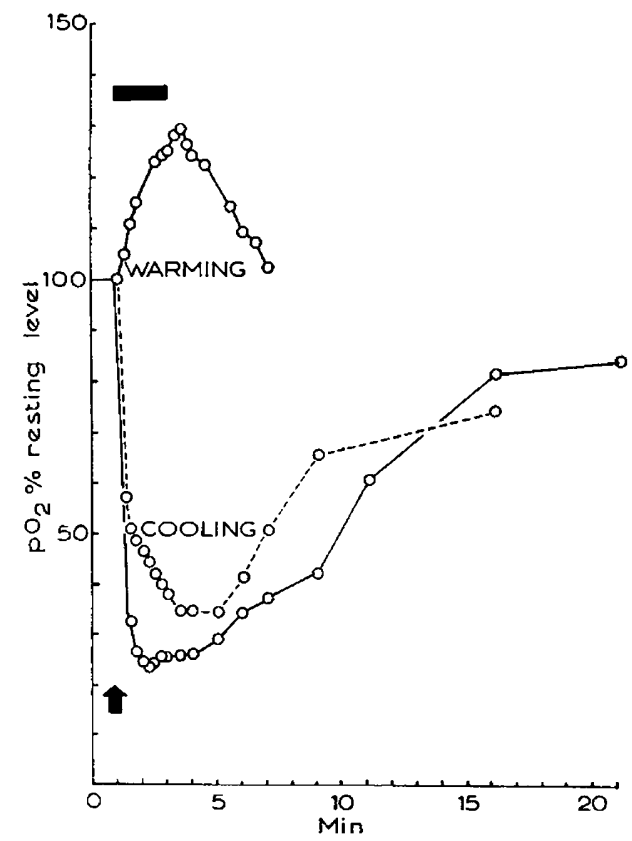

Text-Fig. 7. Effect of warming the scrotum in a stream of hot air and cooling with ethyl chloride spray on the oxygen tension $\left(\mathrm{pO}_{2}\right)$ in the testis of the rabbit. Thoraco-lumbar spinal anaesthesia failed to prevent the response to cooling.

○— $\bigcirc$ Before spinal block; O -... O After spinal block.

\section{Effect of scrotal warming}

The scrotum was warmed by a stream of compressed air escaping through a heated copper coil. Although the stimulus was rather variable, a consistent response occurred in the testis of the rabbit, namely a rise of oxygen tension of 10 to $40 \%$. A typical response can be seen in Text-fig. 7. The adequate stimulus for this effect appeared to be the warming of the scrotal skin since an equivalent heating of the ear produced little change in testis oxygen tension $(<5 \%)$. However, we did not determine if the response was confined to the ipsilateral testis because of the diffuse nature of the heating stimulus. The elevation of 
testis oxygen tension induced by scrotal warming was not prevented by thoracolumbar spinal anaesthesia, and presumably depended upon a local mechanism akin to that involved in the testis response to scrotal cooling. No such consistent effect of scrotal warming was observed in the cauda epididymidis. In this site, the resulting alterations of oxygen tension ranged from $-11 \%$ to $+20 \%$.
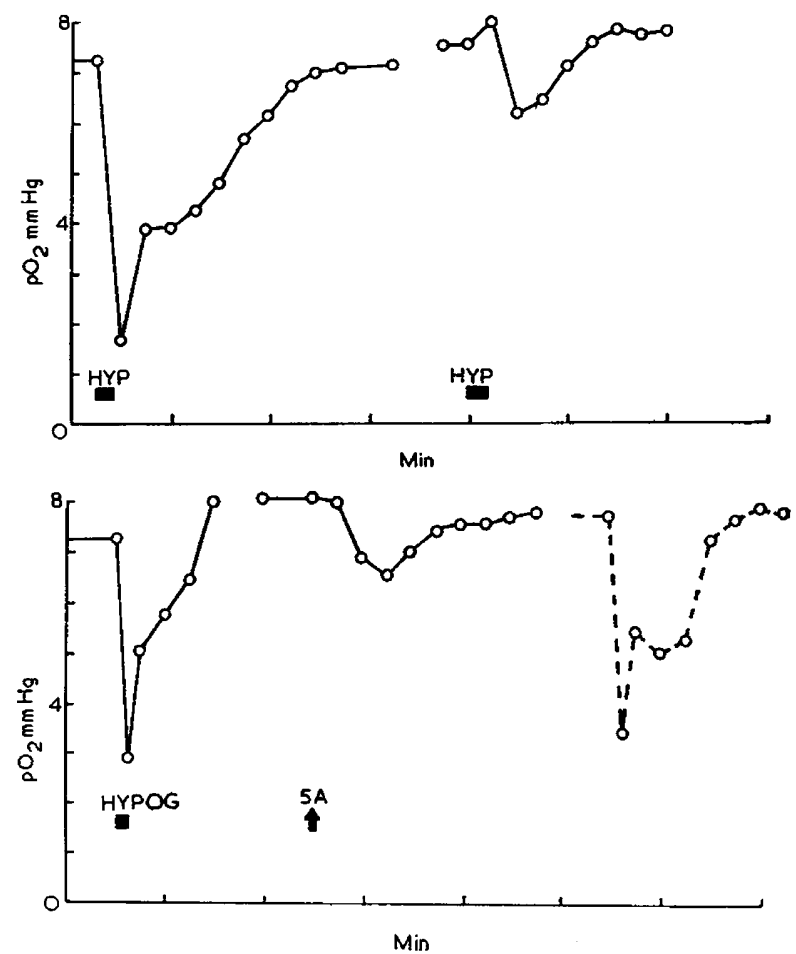

TExT-Fig. 8. Above. Effect of electrical stimulation of the sympathetic area of the hypothalamus (HYP) on testis oxygen tension $\left(\mathrm{pO}_{2}\right)$ in the rabbit before $(l e f t)$ and after $(r i g h t)$ destruction of the posterior mesenteric ganglion and section of the hypogastric nerves.

Below. The lower part shows effects of stimulating the peripheral end of the hypogastric nerve (HYPOG) and of injection intravenously $5 \mathrm{\mu g}$ adrenaline. The dashed curve was obtained by combining the two preceding curves.

In the sheep, as in the rabbit, a moderate rise in testis oxygen tension resulted from scrotal warming, but the cauda epididymidis showed a negligible change. When a fine jet of hot water was used instead of air to warm the scrotum, an interesting diphasic change in testis oxygen tension was recorded. First, there was a $38 \%$ rise similar to that produced by air heating. After recovery to the pre-existing level the oxygen tension showed an almost immediate secondary depression of $20 \%$ associated with cooling, due to evaporation of the water from the surface of the scrotum.

SYMPATHETICO-ADRENAL INFLUENCES ON TESTICULAR BLOOD FLOW

\section{Effects of hypothalamic stimulation}

In previous work with male rabbits, it was shown that electrical stimulation 
of the sympathetic areas of the hypothalamus elicits a vasoconstriction in the testicle as well as contractions of the seminal vesicle, vas deferens and cauda epididymidis, and that these responses involve both direct nervous excitation and adrenomedullary secretion (Cross \& Glover, 1958; Cross, 1959). It was of interest, therefore, to confirm and extend these observations by the use of the oxygen electrode as a sensitive indicator of circulatory changes in the testis. Accordingly, we used the same procedure for stimulation of the hypothalamus in seven rabbits and plotted the resulting oxygen-tension changes in the testes. When the electrodes were suitably placed in the hypothalamus, stimulation produced the familiar range of sympathetic effects including pupillodilation,

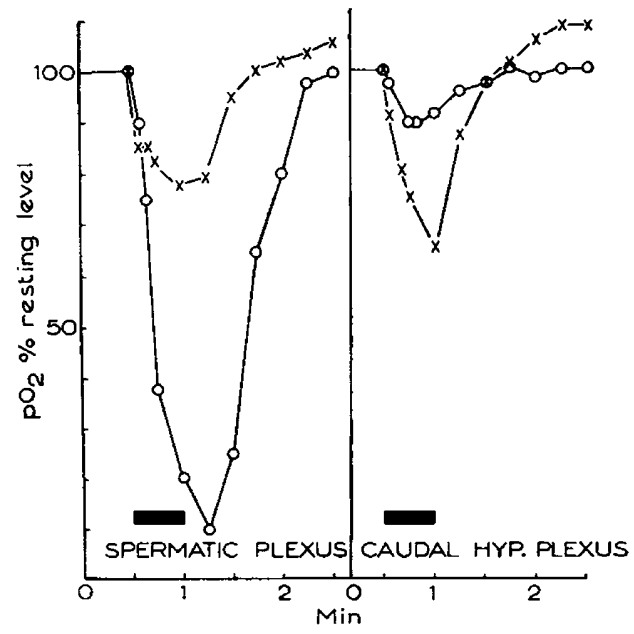

TexT-FIG. 9. Effects of stimulating the internal spermatic plexus and a nerve in the caudal hypogastric plexus on oxygen tension $\left(\mathrm{pO}_{2}\right)$ in the testis and cauda epididymidis of the rabbit.

$\times \longrightarrow \times$ Epididymis; $0-0$ Testis.

exophthalmos and widening of the palpebral fissure, hyperpnoea and tachycardia followed by bradycardia. In every case, a fall in testis oxygen tension occurred. The mean reduction of oxygen tension was $66 \%$ and the range was 28 to $96 \%$. The fall in oxygen tension commenced within a few seconds of the start of stimulation and recovery to normal levels was delayed for 1 to 2 min after the end of the stimulus (Text-figs. 8 and 10). The dual nature of the response is well illustrated in Text-fig. 8, which shows an experiment in which the testis response began as an abrupt fall of oxygen tension during stimulation of the hypothalamus, followed by a partial recovery. The return of oxygen tension was then delayed by a slow secondary depression. In some experiments, an even more pronounced diphasic effect was recorded with the secondary depression of oxygen tension exceeding in magnitude the initial rapid fall. Further study of the mechanism of these hypothalamic effects is described in the ensuing sections.

Experiments were done in four rabbits, three sheep and one dog to find 
the effect of electrical stimulation of various parts of the abdominal sympathetic nerve supply to the testis and epididymis on the oxygen tension in these organs. After laparotomy, the mesocolon was tensed by traction and the posterior mesenteric ganglion and its connexions identified by gentle dissection. In all species, stimulation of the posterior mesenteric ganglion evoked a precipitous fall of testicular oxygen tension which rose again fairly promptly after the end of the stimulus. Text-fig. 4 illustrates a typical effect in a sheep in which the stimulus resulted in a $60 \%$ reduction of oxygen tension in the testis and $40 \%$ in the cauda epididymis. We did not attempt a detailed examination of the hypogastric and spermatic plexuses, but we did get some evidence of a separation of the vasomotor nerve pathways to testis and cauda epididymidis. Thus, in the rabbit experiment shown in Text-fig. 9, it was found that stimulation of the spermatic plexus near the root of the internal spermatic artery elicited a large fall in testis oxygen tension without much affecting the level in the epididymis. On the other hand, the effect of stimulating a nerve in the caudal part of the hypogastric plexus was predominantly in the cauda epididymidis, which suffered a reduction of oxygen tension about three times greater than that occurring in the testis.

Destruction of the posterior mesenteric ganglion and section of the hypogastric nerves eliminated the immediate sharp fall in oxygen tension that previously resulted from electrical stimulation of the sympathetic area of the hypothalamus, as can be seen in Text-figs. 8 and 10. Text-fig. 8 also shows how the appearance of this initial phase of the response could be recreated by stimulation of the peripheral end of the hypogastric nerve. Evidently, the posterior mesenteric ganglion and hypogastric plexus mediate the first part of the testicular response to hypothalamic stimulation.

\section{Effect of endogenous and exogenous adrenaline}

In earlier plethysmographic experiments in rabbits, doses of 0.5 to $10 \mu \mathrm{g}$ adrenaline given intravenously were found to produce definite vasoconstriction in the testicle (Cross, 1955). In the present work, we studied the effect of similar doses of adrenaline on testicular oxygen tension in seven rabbits, two sheep and one dog. A small but consistent depression of testis oxygen tension was seen in all species. In the rabbit, given a dose of $5 \mu \mathrm{g}$ adrenaline, the reduction of oxygen tension varied from 9 to $44 \%$ and the mean was $21 \%$. The latency of the response was 15 to $20 \mathrm{sec}$ and the duration 1 to $3 \mathrm{~min}$ (Text-fig. 8). A comparable reduction occurred in the testis of the sheep and dog following intravenous injection of 10 to $20 \mu \mathrm{g}$ adrenaline. Recordings of oxygen tension in the cauda epididymidis indicated that in all three species adrenaline also evoked a diminution of oxygen tension in this organ though the effect was more variable than that in the testis.

In Text-fig. 8, it can be seen that the secondary depression of testis oxygen tension following electrical stimulation of the sympathetic area of the hypothalamus resembled the response to intravenous injection of $5 \mu \mathrm{g}$ adrenaline. Moreover, a composite graph of oxygen tension constructed from the separate responses to stimulation of the hypogastric nerve and injection of adrenaline was scarcely distinguishable from the original response to hypothalamic 
stimulation. That endogenous secretion of adrenaline was the cause of the delayed effect of hypothalamic stimulation is demonstrated in Text-fig. 10. This shows an experiment in which the delayed effect remaining after section of the hypogastric nerve was abolished by bilateral adrenalectomy. It seemed clear, therefore, that vascular control of testis oxygen tension could emanate from the hypothalamus over both nervous and humoral pathways.

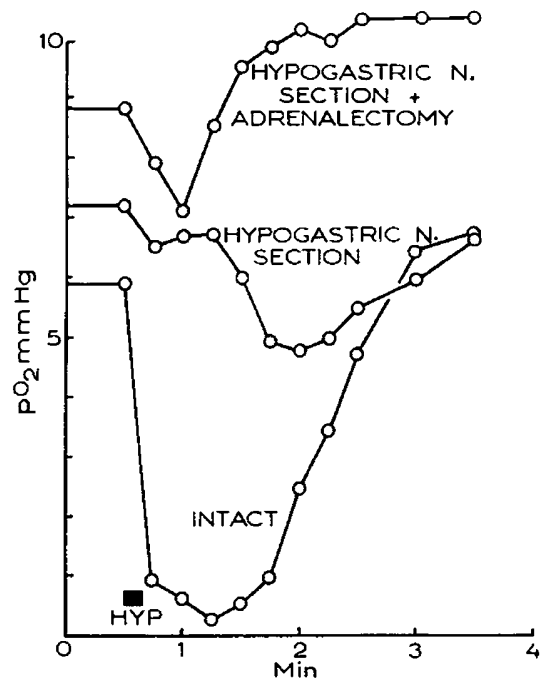

TExT-Fig. 10. Effect of electrical stimulation of the sympathetic area of the hypothalamus on testis oxygen tension $\left(\mathrm{pO}_{2}\right)$ in the rabbit before and after section of hypogastric nerves and bilateral adrenalectomy.

\section{DISCUSSION}

The three major determinants of tissue oxygen tension are the oxygen saturation of the blood, the rate of blood flow in the capillaries and the rate of oxygen uptake by the cells (Kety, 1957). It is obvious that a gradient of oxygen tension must exist between the capillaries and the cells themselves and the tip of our recording electrode may be assumed to register an oxygen tension somewhere on this gradient. The operation of each of the three factors just mentioned can be illustrated from the results of the present experiments. The first, i.e. oxygen saturation of the blood, is demonstrated by the response to oxygen and nitrous oxide breathing (Text-figs. 1 and 2). The second, i.e. capillary blood flow, is shown by the response to vasomotor nerve stimulation (Text-figs. 8 and 9) and adrenaline (Text-fig. 8). Thirdly, the effect of oxygen uptake is reflected in the rapid fall of testis oxygen tension following occlusion of the internal spermatic artery (Text-fig. 3). For practical purposes, under normal conditions of respiration, we may regard short-term changes in oxygen tension recorded from our electrodes as indicative of fluctuations in capillary circulation. This is well shown in Text-fig. 4, which illustrates the comparable depressions of oxygen tension in the testis of the sheep produced by three entirely different stimuli, namely amyl nitrite inhalation, stimulation of the posterior 
mesenteric ganglion and occlusion of the internal spermatic blood vessels. The only feature these stimuli had in common was their ability, by quite dissimilar means, greatly to reduce the flow of blood through the testis.

A discovery of some interest was the regular difference in the resting level of oxygen tension between the testis and cauda epididymidis in the rabbit, sheep and dog. The observation is reminiscent of our findings of oxygen-tension variations in brain tissue where nuclear regions displayed much higher levels than white matter (Cross \& Silver, 1962a). In the latter case, the obvious explanation was the greater capillary density in the nuclei as compared with the relatively avascular nerve tracts, a conclusion that is further supported by work on regional differences in blood flow in the brain with an auto-radiographic technique (Sokoloff, 1961). However, in view of the structural similarity between the testis and epididymis, it is perhaps unlikely that such an explanation could apply to the divergent levels of oxygen tension in these two organs. Differences in capillary supply to the two structures may exist, but none has yet been described. There are two other possibilities. One would be a higher rate of oxygen consumption by the cells of the testis than those of the cauda epididymidis, as might be expected in view of the germinal and secretory activity of the former. Unfortunately, this attractive idea so far lacks experimental support and $\mathrm{Qo}_{2}$ estimations on tissue slices of rat testis and epididymis have not revealed a significant difference between the two organs ( $T$. Mann, personal communication, 1961). The other would be that the oxygen saturation of testicular arterial blood is lower than that of vasal blood. This rather unorthodox notion is favoured by the separation of the vascular supply of the testis and cauda epididymidis (Text-fig. 3 ; Plate 1 ) and by the intimate apposition of the tortuous testicular artery with the veins in the pampiniform plexus. This counter-current arrangement of vessels has already been shown to promote thermal (Dahl \& Herrick, 1959) and pressure (Waites \& Moule, 1960) exchange between the arteries and veins within the plexus, and there seems no reason why some degree of gaseous exchange should not also occur, with a consequent lowering of oxygen saturation in the arterial blood reaching the testis. It should prove a fairly simple matter to decide experimentally which of these possibilities is nearest the truth.

It is customary to regard the scrotum as performing an important thermoregulatory function necessary for the maintenance of optimal conditions in the testis for spermatogenesis (see Bishop \& Walton, 1960). Some authorities suggest that the failure of spermatogenesis in the cryptorchid or heated testis is due to a vascular stagnation with consequential anoxia (Moore, 1924; Harrison, 1956). In this context, our observations on the effects of brief periods of scrotal warming and cooling have a certain relevance. For the reasons already mentioned, we may be reasonably confident that the effects on oxygen tension in the testis and epididymis were the direct result of changes induced in the blood vessels, e.g. a vasodilation in response to scrotal warming and a vasoconstriction in response to scrotal cooling. The mode of production of these vascular effects is more doubtful. The mechanism appears to be highly localized since the contralateral testis is hardly affected, and does not depend upon spinal reflex connexions (Text-fig. 7). As direct cooling of the testis is much less 
effectual than scrotal cooling, it seems likely that cutaneous thermal sense organs are concerned - perhaps in a type of axon reflex. But separate mechanisms may operate in the responses to warming and cooling, for the testicular response to a brief cooling stimulus is much more prolonged than the response to warming. Whatever their mechanism, the further question arises as to how to interpret the functional significance of these well defined testicular effects. Here it must be said that the cooling stimulus used by us was much less severe than those found by others to produce spermatogenic damage in the rat (MacDonald \& Harrison, 1954a, b), guinea-pig (Harris \& Harrison, 1955) and mouse (Payne, 1955), or decapitation of epididymal spermatozoa in rats (Chang, 1943); while our brief warming stimulus could not be expected to reproduce even the transitory sperm damage seen in rams after scrotal insulation for $24 \mathrm{hr}$ (Glover, 1955) and certainly not the complete failure of spermatogenesis occurring after 2 weeks of scrotal insulation (Phillips \& McKenzie, 1934). While it is fairly safe to assume that vascular effects would certainly have occurred under these more extreme conditions, it is difficult to relate them specifically to the changes we have observed. It is possible, however, that the testicular vasodilator effect of scrotal warming might, if continued, lead to a condition of stagnant anoxia, thus giving the same sequence of vascular changes as in the classical picture of inflammation.

At all events, it is clear that, besides the local vascular mechanisms just discussed, the flow of blood in the testis and epididymis can be influenced by vasomotor pathways from the central nervous system and by the circulation of adrenomedullary hormone. Our findings on the effect of stimulating the sympathetic areas of the hypothalamus demonstrate a potential mechanism whereby testicular blood flow may be subordinated to the general circulatory needs of the body. The evidence for the dual pathway from the hypothalamus to the testis and epididymis, i.e. by vasomotor nerves in the hypogastric and spermatic nerve plexuses on the one hand, and humorally via endogenous adrenaline secretion on the other 'Text-figs. 8 and 10), is in good agreement with the earlier results of similar hypothalamic stimulations on contractible activities in the epididymis, seminal vesicle and vas deferens (Cross \& Glover, 1958). In other experiments in rabbits (Cross \& Silver, 1962c), we have found that both these pathways are indeed activated by certain homoral stimuli to the brain, namely hypoxia and hypercapnia, with a resultant vasoconstriction and reduced oxygen tension in the testis. Moreover, bilateral hypothalamic lesions diminsh the effect of these stimuli, so it appears that sympathetic areas of the hypothalamus are an important component of the mechanism. It seems justifiable to infer from these results that, despite the unusual nature of its circulation, the testicle has no special immunity from the demands of cardio-vascular homeostasis. We might expect this hypothalamic mechanism to operate under conditions of natural or simulated high altitude so as to divert blood from less essential organs to the brain and heart, and it is of interest, therefore, that these conditions have been shown to exert a deleterious effect on sperm production in rabbits (Walton \& Uruski, 1946). A possible pharmacological parallel with the foregoing situation might be the reported disruption of spermatogenesis resulting from large doses of adrenaline 
(VanDemark \& Boyd, 1956), although interference other than testicular vasoconstriction, e.g. in the pituitary, might play a part here. In this connexion, the effects produced by physiological doses of adrenaline on testicular blood flow, as judged by the $20 \%$ fall in oxygen tension, were small compared to the effects of similar doses in the mammary gland (Cross \& Silver, 1961b). It seems unlikely that so trivial a change, even if prolonged, would result in testicular damage.

\section{ACKNOWLEDGMENTS}

We are much indebted to our colleague, Donald $H$. Steven for preparing the injected specimens shown in Plate 1, and to Mr Ian Edgar for the radiography. Our best thanks are also due to Mr Derek Thurlbourn and Miss Ann Vipers for skilled technical assistance and for preparing all the Text-figs., and to Miss Valerie Pink for care of the experimental animals. This research was supported by the Air Force Office of Scientific Research of the Air Research and Development Command, United States Air Force, through its European Office, under Contract AF 61(052)-301.

\section{REFERENCES}

Bishop, M. W. H. \& Walton, A. (1960) Spermatogenesis and the structure of mammalian spermatozoa. Marshall's Physiology of Reproduction, 3rd edn, vol. 1, part 2, ed. A. S. Parkes, Longmans Green, London.

Gater, D. B. (1960) Oxygen tension and oxidation-reduction potentials in living tissues. Progr. Biophys. 10, 153 .

CAter, D. B. \& Silver, I. A. (1961) Microelectrodes and electrodes used in biology. Reference Electrodes: Theory and Practice, eds. D. J. G. Ives \& G. J. Janz. Academic Press, New York \& London.

Cater, D. B., Silver, I. A. \& Wilson, G. M. (1959) Apparatus and technique for the quantitative measurement of oxygen tension in living tissue. Proc. roy. Soc., B, 151, 256.

Chang, M. C. (1943) Disintegration of epididymal spermatozoa by application of ice to the scrotal testis. 7. $\exp$. Biol. 20, 16.

Cross, B. A. (1955) The posterior pituitary gland in relation to reproduction and lactation. Brit. med. Bull. 11, 151 .

Gross, B. A. (1958) The motility and reactivity of the estrogenized rabbit uterus in vivo: with comparative observations on milk ejection. 7 . Endocrin. 16, 237.

Cross, B. A. (1959) Hypothalmic influences on sperm transport in the male and female genital tract. Endocrinology of Reproduction, ed. C. W. Lloyd. Academic Press, New York \& London.

Cross, B. A. \& Glover, T. D. (1958) The hypothalamus and seminal emission. 7. Endocrin. 16, 385.

Cross, B. A. \& Silver, I. A. (1962a) Some factors affecting oxygen tension in brain and other organs. Proc. roy. Soc., B (in press).

Cross, B. A. \& Silver, I. A. (1962b) Mammary oxygen tension and the milk-ejection mechanism. 7. Endocrin. 23, 375 .

Cross, B. A. \& Silver, I. A. (1962c) Central activation of the sympathetico-adrenal system by hypoxia and hypercapnia. F. Endocrin. 24, 91.

DAHL, E. V. \& HERRICK, J. F. (1959) A vascular mechanism for maintaining testicular temperature by counter-current exchange. Surg. Gynec. Obstet. 108, 697.

Grover, T. D. (1955) Some effects of scrotal insulation on the semen of rams. Studies on Fertility, vol. 7, p. 66, ed. R. G. Harrison. Blackwell Scientific Publications, Oxford.

HARRIs, R. \& HARRISON, R. G. (1955) The effect of low temperature on the guinea-pig testis. Studies on Fertility, vol. 7, p. 23, ed. R. G. Harrison, Blackwell Scientific Publications, Oxford.

HARRison, R. G. (1956) Factors influencing the process of spermatogenesis in the experimental animai Brit. J. Urol. 28, 422.

Harrison, R. G. (1949) The distribution of the vasal and cremasteric arteries to the testis and their functional importance. 7. Anat., Lond. 83, 267. 
Joranson, Y., Emmel, V. E. \& Pilka, H J. (1929) Factors controlling the arterial supply of the testis under experimental conditions. Anat. Rec. 41, 157.

KeTY, S. S. (1957) Determinants of tissue oxygen tension. Fed. Proc. 16, 666.

MacDonald, J. \& Harrison, R. G. (1954a) Effect of low temperature on rat spermatogenesis. Fertil. E Steril. 5, 205.

MacDonald, J. \& Harrison, R. G. (1954b) Histological appearances in the rat testis following exposure to low temperatures. Studies on Fertility, vol. 6, p. 14, ed. R. G. Harrison. Blackwell Scientific Publications, Oxford.

Moore, C. R. (1924) Heat application and testicular degeneration; the function of the scrotum. Amer. 7. Anat. 34, 337.

PAyne, J. M. (1955) An experimental study of injury and bacterial infections of the scrotal and cryptorchid testis. F. Path. Bact. 70, 213.

Phillips, R. W. \& MaKenzie, F. F. (1934) The thermoregulatory function and mechanism of the scrotum. Res. Bull. Mo. agric. exp. Sta., No. 217.

Sawyer, C. H., Green, J. D. \& Everett, J. W. (1954) The rabbit diencephalon in stereotaxic coordinates. 7. comp. Neurol. 101, 801.

Sokoloff, L. (1961) Local cerebral circulation at rest and during altered cerebral activity induced by anaesthesia or visual stimulation. Regional Neurochemistry, eds. S. S. Kety \& J. Elkes. Pergamon Press, Oxford.

VanDemark, N. L. \& Boyd, J. L. (1956) The effect of epinephrine upon testicular function in rabbits. Int. 7. Fertil. 1, 245.

Waites, G. M. \& Moule, G. R. (1960) Blood pressure in the internal spermatic artery of the ram. 7. Reprod. Fertil. 1, 223.

Walton, A. \& URUSkr, W. (1946) The effects of low atmospheric pressure on the fertility of male rabbits. F. $\exp$. Biol. 23, 71 . 